ESPAÇO TEMATICO: PROTEÇÃO SOCIAL NO CAPITALISMO CONTEMPORÂNEO:

CONTRARREFORMAS E REGRESSÕES DOS DIREITOS SOCIAIS

\title{
Renda mínima e proteção social: aspectos históricos, teóricos e conjunturais
}

\author{
Robson Roberto da Silva ${ }^{\mathbf{1}}$ \\ https://orcid.org/0000-0003-0699-853X \\ ${ }^{1}$ Universidade Federal Fluminense, Departamento de Serviço Social, Niterói, RJ, Brasil
}

\section{Renda mínima e proteção social: aspectos históricos, teóricos e conjunturais}

Resumo: Este trabalho busca analisar a trajetória dos programas/propostas de renda mínima e a sua relação com os padrões de proteção social, considerando os aspectos históricos, teóricos e conjunturais. Para tanto, utilizou-se a pesquisa bibliográfica como recurso metodológico para identificar e conhecer as informações e discussões, que foram analisadas à luz da perspectiva crítico-dialética. Assim, procura demonstrar que as propostas e os programas surgem e ampliam-se em determinados contextos como forma de contribuir com a reprodução material da força de trabalho e principalmente do capital. A criação dessas estratégias envolve a participação de sujeitos com distintas posições teóricas e ideopolíticas. Nos países centrais, elas têm sido construídas articuladas aos Estados de Bem-Estar Social, orientam-se por diferentes correntes teóricas e complementam as provisões de serviços e outras prestações sociais monetárias. Entretanto, na América Latina, os sistemas de proteção social inconclusos vêm cedendo lugar aos programas de renda mínima, que surgem tardiamente na região.

Palavras-chave: Renda mínima. Proteção social. Capitalismo. Países centrais. América Latina.

\section{Minimum income and social protection: historical, theoretical and contextual aspects}

Abstract: This article analyzes the history of the minimum income programs and proposals, observing the relationship with social protection standards and taking into account historical, theoretical and contextual aspects. The study used bibliographical research to identify and obtain information and to understand the discussions around the theme, adopting a critical-dialectical perspective. It, therefore, demonstrates that proposals and programs appear and expand in specific contexts as a way of contributing to the material reproduction of the labor force and especially of capital. The minimum income programs are created with the participation of subjects with different theoretical background and political ideology. In developed countries, they have been built connected to the Welfare States, and are guided by different theoretical currents, complementing the services provided and other monetary social benefits. In Latin America, the incomplete social protection systems are being replaced by minimum income programs, which appeared later in the region.

Keywords: Minimum income. Social protection. Capitalism. Developed countries. Latin America.

Recebido em 01.06.2018. Aprovado em 18.09.2018. Revisado em 18.01.2019.

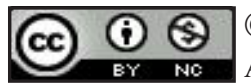

(C) O(s) Autor(es). 2019 Acesso Aberto Esta obra está licenciada sob os termos da Licença Creative Commons Atribuição-NãoComercial 4.0 Internacional (https://creativecommons.org/licenses/by-nc/4.0/deed.pt_BR), que permite copiar, distribuir e reproduzir em qualquer meio, bem como adaptar, transformar e criar a partir deste material, desde que para fins não comerciais e que você forneça o devido crédito aos autores e a fonte, insira um link para a Licença Creative Commons e indique se mudanças foram feitas. 


\section{Introdução}

Este trabalho busca analisar a trajetória dos programas de renda mínima, incluindo as propostas, e a sua relação com os padrões de proteção social, considerando os aspectos históricos, teóricos e conjunturais. Assim, procura compreender as principais propostas de renda mínima de sujeitos com posições teóricas e ideopolíticas; as primeiras formas e os programas dessa natureza, que surgem como respostas às transformações econômicas, políticas e sociais que marcam os diferentes estágios do capitalismo: comercial; concorrencial e monopolista. Particularmente, o trabalho se propõe a compreender a relação dos programas de renda mínima com os distintos padrões de proteção social dos países centrais e latino-americanos, partindo do pressuposto que contribuem para a reprodução material da força de trabalho e principalmente do capital.

Para tanto, utilizou-se a pesquisa bibliográfica como recurso metodológico para identificar e compreender as informações e discussões, que foram analisadas à luz da perspectiva crítico-dialética. O resultado dessa investigação apresenta-se neste trabalho, que está organizado de forma articulada em quatro seções: a primeira procura tratar das propostas de renda mínima e das Leis dos Pobres (Poor Laws), sobretudo da Speenhamland Law de 1795 (POLANYI, 1980), nos dois primeiros estágios do capitalismo; a segunda busca compreender, na fase do capitalismo monopolista, as propostas e programas que surgem e se desenvolvem nos países centrais articulados aos Estados de Bem-Estar Social; o destaque é dado na terceira seção à ampliação das propostas e programas de renda mínima e às correntes teóricas que as(os) orientam no contexto da crise, iniciada em 1970, que envolve a estrutura do capital; por fim, busca entender o surgimento, as características das propostas e programas de renda mínima e as configurações que os sistemas de proteção social inconclusos da América Latina assumem com a centralidade deles no campo das provisões de serviços e das outras prestações sociais monetárias de muitos países da região.

\section{As propostas de renda mínima e as Leis dos Pobres nos estágios iniciais do capitalismo}

No curso do primeiro estágio do capitalismo, que surge e se desenvolve entre o século XVI e o meado do século XVIII com a chamada acumulação primitiva e o estabelecimento posteriormente da manufatura, a burguesia afirmou-se como classe revolucionária, que passou a controlar as principais atividades econômicas e a confrontar os privilégios da nobreza fundiária.

Nesse estágio do capitalismo denominado de comercial ou mercantil, a obra Utopia, de Thomas More, é publicada em Louvain, na Bélgica, em 1516. Nela, More (2004), um humanista inglês, apresenta uma análise crítica das particularidades do feudalismo em declínio na Inglaterra, ressaltando o papel do Estado, as guerras de conquistas e as expansões/relações territoriais, a expulsão dos camponeses do campo, o uso de outras práticas coercitivas, os conflitos e intolerâncias religiosas, as desigualdades e injustiças da época, propondo também uma sociedade alternativa que considerava como perfeita. Além disso, apresenta uma primeira noção de renda mínima, que foi sugerida como um mecanismo que poderia evitar na sua concepção a pena de morte. "Os ladrões são condenados a um suplício cruel e atroz, quando seria preferível assegurar a subsistência de cada um, de maneira a que ninguém se encontrasse diante da necessidade de roubar para ser, em seguida, executado." (MORE, 2004, p. 13).

De acordo com Suplicy (2004, p. 52), More “[...] fez uma proposta visionária de instituição de uma renda para todos, de forma que tivessem um meio de sobrevivência". Sua obra Utopia contribuiu para que outros humanistas se debruçassem sobre a concepção de renda mínima apresentada nesse livro, como Johannes Ludovicus Vives, um humanista de origem judia catalã e professor em Louvain, que criou, em 1526, o primeiro plano de uma renda mínima garantida denominado de De Subventione Pauperum, que corresponde a uma proposta escrita para o prefeito da cidade Flamenga de Bruges, na Bélgica, mas que foi instituída em uma outra cidade desse país, em Ipres, nesse mesmo período (SUPLICY, 2004, 2006).

A implementação desse plano traduziu-se em uma caridade do governo local, que passou a adquirir a legitimidade de ajudar os pobres, pois, segundo Vives ([2017]), as esmolas dadas de livre vontade eram mais bem distribuídas pelo município que elegia apenas os mais necessitados e ainda exigia desses a prestação de alguma contrapartida em trabalho, haja vista que o ócio não era permitido: "A nenhum pobre que, por causa de sua idade e saúde, possa trabalhar deve-se permitir ficar ocioso [...]" (VIVES, [2017], p. 32, tradução nossa). $\mathrm{O}$ autor também defende que: "Aqueles que ainda não foram destinados a alguma casa ou mestre sejam alimentados por algum tempo, em algum lugar, das esmolas que são arrecadadas, mas enquanto isso não devem deixar de trabalhar, para que do lazer não aprenda a preguiça [...]" (VIVES, [2017], p. 33, tradução nossa). Mais tarde, outros municípios europeus começaram a implantar formas parecidas de ajuda pública ou caridade aos pobres. Em 1531, várias experiências foram sendo construídas nos Países Baixos; na Escócia, em 
1579, e depois na Inglaterra, em 1601, com a promulgação das Leis dos Pobres (SILVA, M., 1997; SUPLICY, 2004; VANDERBORGHT; VAN PARIJS, 2006).

Segundo Polanyi (1980, p. 101), com essas Leis “[...] os pobres eram forçados a trabalhar com qualquer salário que pudessem conseguir e somente aqueles que não conseguiam trabalho tinham direito à assistência social". Logo, foram mais punitivas do que protetoras. Uma delas, a Speenhamland Law (POLANYI, 1980) - criada em 1795 em Speen em decorrência das revoltas do pão que surgiram com o problema da fome neste município do sul da Inglaterra - transferia um abono financeiro complementar ao salário dos trabalhadores, independente dos seus proventos, cujo cálculo se dava a partir do número de filhos e do preço do pão, mas como contrapartida proibia a mobilidade geográfica dos trabalhadores, que precisavam trabalhar ou serem assistidos nas paróquias. A transferência dessa renda mínima serviu de inspiração para que outras cidades, na Inglaterra, adotassem medidas parecidas, que exigiam contrapartidas.

Entretanto, na segunda metade do século XIII, o ca-

\section{[...] intensificam-se no começo} do século XXI os ataques às políticas de proteção social vinculadas aos direitos do trabalho, que vêm acompanhado de um crescimento das provisões de serviços e prestações monetárias assistenciais, impondo assim limites ao próprio princípio de complementariedade dos programas de renda mínima. Na América Latina, esse é um processo que não é novo, pois os programas de renda mínima nascem tardiamente em um contexto marcado pela privatização e mercantilização das políticas constitutivas dos seus sistemas de proteção social inconclusos [...]

pio da justiça social. Por isso, apontavam a necessidade de criar estratégias para eliminar a propriedade privada - para Spence, o leilão de imóveis, e para Fourier, a transferência das propriedades fundiárias para o pitalismo entra no seu segundo estágio denominado de concorrencial, liberal ou clássico. A entrada do capitalismo nessa nova fase está associada aos processos políticos forjados pela Revolução Burguesa, que estava concluindo-se com a tomada do poder de Estado pela burguesia; e às transformações econômicas que culminaram na chamada Primeira Revolução Industrial. A partir desse momento, o capital passou a organizar a produção nos moldes da indústria moderna e a promover a subsunção real do trabalho. Assim, o capitalismo concorrencial consolidou-se nos principais países da Europa Ocidental, que passaram por processos de urbanização sem precedentes; e, liderados pela Inglaterra, participaram da construção do mercado mundial. (PAULO NETTO; BRAZ, 2006).

Nesse contexto, destaca-se o surgimento do movimento intelectual e filosófico que ao longo do século XVIII ficou conhecido como iluminismo. Thomas Paine foi um dos pensadores e das lideranças políticas desse movimento, que defendiam valores liberais e que influenciaram a Revolução Burguesa. Dentre as suas produções teóricas destaca-se um guia das ideias iluministas (Rights of Man), de 1791, e o ensaio Justiça Agrária (Agrarian Justice), de 1795, onde defendia a garantia de uma renda mínima igual para todos os homens e mulheres que completassem 21 anos de idade e anualmente às pessoas que tivessem com 50 anos ou mais (SUPLICY, 2006). Tal renda deveria ser paga por meio de um fundo nacional proveniente de recursos arrecadados de proprietários de terras pelo o cultivo. Assim, Euzeby (1991, p. 27 apud SILVA, M., 1997, p. 27) aponta que Paine, “[...] referindo-se à justiça agrícola, desenvolve a ideia de que a terra é um bem comum, cuja apropriação por uns justifica o estabelecimento de uma renda mínima para todos".

Nota-se dessa maneira que Paine, apesar de propor uma renda mínima universal, não sugere o fim da propriedade privada: considerada aqui um elemento fundante da desigualdade. Desde o começo do século XIX, sua proposta de um dividendo igual para todos influenciou diferentes pensadores, como também despertou críticas de outros, principalmente de teóricos do socialismo utópico de diferentes países: Thomas Spence, na Inglaterra; Charles Fourier, na França; e Joseph Charlier, na Bélgica, que compreendiam em linhas gerais que o surgimento da propriedade privada violou direitos naturais e/ou que era incompatível com o princí- 
Estado, que cobraria uma taxa pelo o seu uso - de modo que a renda arrecadada deveria ser transferida em parte igual para todos ${ }^{1}$ (VANDERBORGHT; VAN PARIJS, 2006).

Para os pensadores liberais clássicos, como Adam Smith, David Ricardo, John Stuart Mill, Jeremy Benthan e Thomas Malthus, as Leis dos Pobres e as propostas de um dividendo igual para todos configuravamse como um obstáculo à ordem capitalista, que partia do pressuposto da autorregulação do mercado (POLANYI, 1980; SUPLICY, 2004; VIANNA, 2002). Não por acaso, desde o século XVIII, a Speenhamland Law sofreu duras críticas pelos liberais, que a compreendiam como impedimento à construção do mercado nacional competitivo de trabalho e ineficaz para alcançar o bem-estar social: esse poderia ser atingido pela chamada "[...] mão invisível" do mercado (SMITH, 1983, p. 379). Essas críticas contribuíram para a criação da Lei Revisora das Leis dos Pobres, ou Nova Lei dos Pobres (Poor Law Amendment Act), de 1834, que extinguiu a Speenhamland Law (POLANYI, 1980; VIANNA, 2002).

A partir desse momento, a situação social dos pauperizados agravou-se, haja vista que "[...] esperava-se, agora, que o pobre garantisse sozinho a sua sobrevivência, contra todas as desvantagens que a economia de mercado lhe impunha". (PEREIRA, 2006, p. 106). Para denominar o fenômeno do pauperismo, que contribuiu para o ingresso da classe trabalhadora no cenário político, exigindo o seu reconhecimento como classe por parte dos empresários e do Estado, surge na terceira década do século XIX o termo questão social, que é indissociável do capitalismo. Atreladas a essas transformações que ocorrem no âmbito político, outros processos marcaram a segunda metade desse século, como o desenvolvimento das ciências naturais decorrente das demandas das indústrias, cujo impacto na produção marcou o surgimento de uma segunda revolução industrial; e na sequência da crise sistêmica/estrutural ${ }^{2}$ de 1873 a criação dos monopólios, que acompanhou o surgimento do capital financeiro.

Como uma das tendências desse terceiro estágio do capitalismo (o monopolista), que Lenin (2012) chamou de imperialismo, destaca-se a dificuldade de valorização do capital acumulado, que passou a depender da ampliação e alteração das funções do Estado. Nesse contexto, as propostas de renda mínima surgem nos argumentos de pensadores do liberalismo heterodoxo, que defendiam a regulação do Estado na economia, de fundadores do neoliberalismo, de teóricos progressistas, e aparecem nas reivindicações de determinados movimentos sociais e partidos políticos. Assim, como parte de um amplo acordo entre capital e trabalho, os primeiros programas surgem articulados com a construção dos Estados de Bem-Estar Social (Welfare States).

\section{Welfare States, propostas e programas de renda mínima no capitalismo monopolista}

No capitalismo monopolista, a ampliação e alteração das funções do Estado no começo do século XX estão relacionadas ao enfraquecimento das bases objetivas e subjetivas que davam sustentação aos argumentos do liberalismo clássico ou ortodoxo. Behring e Boschetti (2006) mencionam que este enfraquecimento está ligado a processos político-econômicos, dos quais destacam ao menos dois: o primeiro foi o crescimento do movimento operário que passou a ocupar espaços políticos importantes e conseguiu pressionar a burguesia, fazendo com que esta reconhecesse os direitos políticos e sociais; e o segundo diz respeito ao processo de concentração e monopolização do capital, que, a partir de suas concorrências internacionais ou intercapitalistas, originou duas grandes guerras mundiais (a primeira datada de 1914-1918 e a segunda de 1939-1945) e entre essas a crise de 1929 que envolveu toda a estrutura da ordem do capital.

Nesse contexto, a proposta de uma renda mínima igual para todos é defendida por determinados movimentos sociais e partidos políticos, como o Movimento pelo Crédito Social, na Inglaterra, e o Partido do Crédito Social, no Canadá; e aparece nas obras de distintos teóricos, filosóficos e economistas, com posições à direita ou à esquerda no espectro político. A exemplo, John Maynard Keynes (1940) - considerado um liberal heterodoxo por defender a intervenção do Estado na economia e não acreditar, portanto, na falácia da autorregulação do mercado - propôs uma renda básica a todos, como também Friedrick Hayek, fundador da doutrina neoliberal ou ultraliberal, em $O$ caminho da servidão, de 1944, "[...] ao criticar o comunismo, o nazismo e o fascismo, [...] defende o sistema de mercado, mas salientando ser importante assegurar a todos a sua subsistência". (SUPLICY, 2006, p. 47). Porém, no caso de Hayek (1990), não se trata de uma renda mínima universal e nem de um sistema redistributivo, haja vista que para ele o bem-estar social depende dos esforços dos indivíduos e não do Estado.

Entretanto, as bases objetivas e subjetivas não davam também suporte para utilização do neoliberalismo. Por essa razão, os Estados passaram a seguir nesse contexto as orientações do pensamento keynesiano e particularmente a implementar políticas sociais, que contribuíram nos países centrais para que fossem chamados de Estados de Bem-Estar Social (VIANA; LEVCOVITZ, 2005). Porém, isso não significou que assumissem uma natureza anticapitalista, pois permaneceram participando do processo de reprodução material da força de trabalho e principalmente do capital (BOSCHETTI, 2009). Também não significou que seus padrões de proteção social apresentassem as mesmas características, posto que as políticas sociais oriundas do conflito 
entre capital e trabalho vêm conformando distintos sistemas de proteção social, que assumem particularidades em decorrência das condições estruturais e conjunturais de cada país e da forma como esses se inserem no sistema capitalista mundial. Logo, são padrões híbridos, sendo '[...] difícil encontrar um 'modelo puro'. As políticas existentes e que constituem os sistemas de seguridade social em diversos países apresentam as características dos dois modelos (bismarckiano e beveridgeano), com maior ou menor intensidade". (BOSCHETTI, 2009, p. 325).

Os programas de renda mínima surgem e desenvolvem-se articulados aos Estados de Bem-Estar Social, como complemento as provisões de serviços (saúde, educação, moradia etc.) e de outras prestações sociais monetárias (seguro-desemprego, aposentadoria, pensões etc.). Em 1948, o Reino Unido, que construiu o padrão beveridgeano de seguridade social de referência mundial, implantou o National Assistance Act, um programa de renda mínima para todas as famílias que atendia às necessidades de subsistência e complementava o sistema ampliado de proteção social. Na Finlândia, em 1956, na Suécia, em 1957, e nos Países Baixos, em 1963, também foram criados programas de renda mínima complementares às politicas de seguridade social. Desde 1957, na Alemanha, o padrão bismarckiano (que influenciou outros países centrais e periféricos) conta com um programa de renda mínima complementar para suprir necessidades diárias, por tempo ilimitado, a todos os indivíduos que se considerem pobres, com exceção dos imigrantes ilegais (LAVINAS, 1998; VANDERBORGHT; VAN PARIJS, 2006).

Nos Estados Unidos (EUA), em 1935, é criado o Social Security Act constituído por seguro desemprego, aposentadorias, pensões e assistência social. No interior desse sistema de proteção social é instituído no mesmo ano o Programa de Auxílio às Famílias com Crianças Dependentes (Aid for Families with Dependent Children), que transferia uma renda mínima para famílias com crianças e com renda abaixo de um patamar. Em 1964 surgiu o programa Food Stamps, que fornece um bônus aos adultos desempregados para compra de elementos em estabelecimentos conveniados. No ínterim desses dois programas nascem propostas (por parte de economistas liberais) de construção de um Imposto Negativo: em 1944, por Abba Lerner e, em 1962, pelo neoliberal Milton Friedman (VANDERBORGHT; VAN PARIJS, 2006).

A proposta do Imposto Negativo diz respeito à transferência de uma renda mínima, que seja incapaz de criar um estímulo ao ócio, mas sim ao trabalho. Para tanto, seria construída uma linha de pobreza, os indivíduos que estivessem acima dela pagariam um imposto e os que estivessem abaixo receberiam uma renda mínima complementar a renda alcançada através do trabalho (SILVA, M., 1997). Uma experiência concreta de Imposto Negativo foi desenvolvida nos Estados Unidos, em 1974, com a implementação do Crédito Fiscal por Remuneração Recebida (Earned Income Tax Credit) (SILVA, M.; YAZBEK; DI GIOVANNI, 2004).

Nos Estados Unidos e em outros países centrais ou periféricos que construíram estruturas de proteção social, caracterizadas principalmente por políticas sociais focalizadas ou pouco abrangentes, os programas de renda mínima têm sido os primeiros a serem acionados pelos trabalhadores e suas famílias, assumindo assim uma centralidade no campo das provisões de serviços e prestações sociais monetárias. A situação altera-se nos países da Europa, cujos sistemas de proteção social são marcados, sobretudo, por políticas sociais universais e/ou por políticas que seguem a lógica do padrão bismarckiano, mas que possuem uma cobertura ampla. Nesses países, os programas são os últimos recursos a serem acionados (STEIN, 2008; COBO, 2012).

Durante o segundo pós-guerra mundial, os programas de renda mínima vinculados aos sistemas de proteção social contribuíram com a ampliação do mercado de consumo e com o crescimento econômico. Assim, a política keynesiana articulou-se com a produção em série e em massa do fordismo em construção desde o início do século XX. Entretanto, em resposta a crise sistêmica/estrutural do capitalismo que emergiu na década de 1970, começou a ser construído um novo regime de produção denominado por Harvey (2011, p. 140, grifo do autor) de "acumulação flexível", que sob a hegemonia do capital financeiro passou a exigir outra forma de organização e atuação do Estado, com clara orientação neoliberal. Nesse cenário, ampliam-se as propostas e as experiências de programas de renda mínima nos países centrais, que se orientam por correntes de distintas matrizes teóricas, posto que, com a crise que evolveu a estrutura do capital, as expressões da questão social (desemprego, pobreza etc.) se agravaram; ao mesmo tempo, em que os Estados de Bem-Estar Social passaram apresentar dificuldades para manter o escopo e a cobertura das suas estruturas de proteção social, que não foram desmontadas por completo, mas foram alvo de contrarreformas $^{3}$ que serviram como amortizadores da crise (VIANNA, 2000).

\section{Ampliação e correntes teóricas das propostas e programas de renda mínima nos países centrais}

Segundo Silva, M. (1997), as propostas e os programas que se ampliam nesse contexto orientam-se por correntes de distintas matrizes teóricas. A proposta de Renda Básica de Cidadania, incluindo aqui a experiência 
concreta do Alasca, nos EUA, implementada desde o início dos anos 1980, defendida por diversos intelectuais e lideranças políticas, como Van Parijs; o Imposto Negativo, de Milton Friedman; e o programa Crédito Fiscal por Remuneração Recebida criado também no EUA em 1974 orientam-se, de acordo com a autora, principalmente pela corrente de inspiração liberal. Tal corrente defende a transferência de uma renda mínima paga, individualmente, para todos, sem qualquer restrição ou contrapartida, a partir de alguns argumentos, como: a substituição dos sistemas de proteção social.

A Renda Social, de André Gorz, e outras propostas fundadas na distribuição de riqueza orientam-se, sobretudo, pela corrente denominada em Silva, M. (1997) de distributivista ou progressista. Essa, segundo a autora, possui um conjunto de argumentos para a efetivação da transferência de uma renda mínima universal, incondicional, por tempo ilimitado, complementar e atrelada à flexibilização dos períodos e horários de trabalho e à redistribuição da redução da jornada de trabalho para que todos possam trabalhar. Dentre os seus argumentos destacam-se aqui: a complementação dos serviços e outras prestações monetárias dos sistemas de proteção social.

A proposta de Renda Social de Inserção de Milano e o Programa de Renda Mínima de Inserção (RMI), implementado na França desde 1988, orientam-se, principalmente, pela corrente que defende a inserção a partir de uma transferência de renda mínima, individual, por tempo limitado, condicional e complementar. No âmbito dos seus argumentos, nota-se que os programas devem promover a articulação da renda com os serviços e outras prestações monetárias, de modo a reforçar a complementação dos sistemas de proteção social; e a associação do direito à renda mínima com o direito à inserção profissional e social (SILVA, M., 1997).

Embora esse esforço de compreender as correntes teóricas que mais orientam as propostas e programas de renda mínima nos países centrais não seja algo desprezível, ele não anula outros traços teórico-práticos e ideopolíticos dessas medidas, que por serem uma realidade concreta e complexa também assumem assim um formato híbrido. Em outras palavras, esse exercício "[...] ao mesmo tempo que cobrem as diferentes dimensões fundamentais do debate, apresentam convergências nos seus esforços classificatórios". (SILVA, M., 1997, p. 40). Entretanto, há um movimento internacional que visa debater as experiências de renda mínima e defender a implantação de uma renda básica incondicional em muitos países. Como parte desse movimento, surgiu, em 1986, a Rede Europeia da Renda Básica (Basic Income European Network), transformada, em 2004, em Rede Mundial da Renda Básica (Basic Income Earth Network [BIEN]). Apesar das críticas à renda básica, Suplicy (2004, p. 101) é um dos integrantes da BIEN e defensor da implementação dessa renda, que para ele "[...] complementa, e não substitui transferências nas formas de bens e serviços existentes, como os da educação e da saúde públicas".

$\mathrm{Na}$ Europa, mesmo com a diversidade de experiências de renda mínima e dos limites institucionais e estruturais de muitas delas - o RMI, por exemplo, não atende os jovens com idade inferior a 25 anos e o problema do desemprego é também estrutural na França, em particular entre os jovens -, é consenso de que todas elas complementam os serviços e outras prestações monetárias dos distintos sistemas de proteção social. "Os programas são complementares (não são substitutivos de outros direitos sociais) e realizam-se como uma alocação monetária complementar e diferencial.” (FONSECA, 2001, p. 151). Contudo, intensificam-se no começo do século XXI os ataques às políticas de proteção social vinculadas aos direitos do trabalho, que vêm acompanhado de um crescimento das provisões de serviços e prestações monetárias assistenciais ${ }^{4}$, impondo assim limites ao próprio princípio de complementariedade dos programas de renda mínima. Na América Latina, esse é um processo que não é novo, pois os programas de renda mínima nascem tardiamente em um contexto marcado pela privatização e mercantilização das políticas constitutivas dos seus sistemas de proteção social inconclusos, que não podem ser igualados aos Estados de Bem-Estar Social.

\section{A renda mínima na América Latina: surgimento, características e configurações da proteção social}

As primeiras formas de proteção social prestadas pelo Estado surgem na América Latina em 1920 com o aprofundamento do conflito entre capital e trabalho impulsionado pela industrialização tardia, que não rompeu com a sua condição subalterna e dependente com o capitalismo mundial (FLEURY, 1994; PASTORINI, 2010). Destaca-se no período de surgimento a forte influência do padrão de seguro bismarckiano, que ainda hoje se faz presente e que convive com outras características dos sistemas de proteção social desenvolvidas em razão das singularidades de cada país.

A partir do meado dos anos 1970, a crise estrutural do capitalismo trouxe graves consequências para esses países, que passaram a conviver ao mesmo tempo com processos de transição política que perdurou até o começo da década de 1990. Segundo Fleury (1994), a existência desses dois processos concorrentes e simultâneos orientou dois modelos distintos de reformas dos sistemas de proteção social em disputa: o modelo universal/ 
publicista e o liberal/produtivista. No Brasil, a introdução da noção de seguridade social (inspirada na experiência europeia do Welfare State) na Constituição Federal de 1988, que alterou em parte o padrão de seguro social - pois a saúde legalmente passou a ser uma política universal, a assistência social uma política pública para aqueles que dela necessitarem e a previdência social permaneceu seguindo a lógica da contribuição versus benefício -, significou, ao menos formalmente, uma vitória dos sujeitos progressistas, haja vista que a seguridade social brasileira, apesar de assumir um padrão híbrido e inconcluso, apresenta, principalmente, características legais de um modelo universal/publicista, o que não acorreu no Chile com a experiência piloto do neoliberalismo.

Essa primeira experiência no Chile, com o golpe de Pinochet contra o governo democraticamente eleito de Salvador Allende, serviu como referência para a utilização do neoliberalismo nos Estados Unidos, na Europa e em outros países centrais e periféricos. Segundo Harvey (2008), a experiência da neoliberalização foi marcada por uma série de idas e vindas e de experimentos caóticos e desiguais, que levou a elaboração no ano de 1989, em Washington, nos EUA, de uma nova ortodoxia conhecida como Consenso de Washington. Essa foi defendida por organismos multilaterais e lideranças políticas conservadoras dos países centrais e periféricos; e passou a ser adotada na América Latina a partir dos anos 1990 como uma forma de desobstruir os empecilhos à expansão do capital. No começo do século XXI, determinados países da região, como o Brasil e o próprio Chile, passaram a manter a doutrina neoliberal pela via do social-liberalismo; porém, com os recentes golpes institucionais, parlamentares e midiáticos, a ortodoxia neoliberal tem sido reafirmada em muitos países.

Nesse contexto pós-1990 - caracterizado também por transformações na economia decorrentes da reestruturação produtiva, que trouxe mudanças no mundo trabalho -, agravaram-se as expressões da questão social. A Comissão Econômica para a América Latina e o Caribe (CEPAL) (2007), ao analisar a evolução da pobreza e da indigência na América Latina entre 1980-2006, constatou que as maiores estimativas, em termos percentuais, foram as da década de 1990. Em resposta a esse aumento da pobreza e da extrema pobreza e como desdobramento das contrarreformas dos sistemas de proteção social inconclusos, que foram guiadas pelos princípios do ideário neoliberal para as políticas sociais (focalização, descentralização e privatização), surgem na região os primeiros programas de renda mínima condicionada.

A primeira iniciativa foi na Venezuela, em 1989, com a implementação do Programa Beca Alimentaria. Na primeira metade dos anos 1990, nasce no Brasil as propostas de uma renda básica de cidadania (1991) e as experiências de renda mínima em municípios e estados, como a do Distrito Federal, a de Campinas e de Ribeirão Preto, essas duas últimas no estado de São Paulo (STEIN, 2008; SILVA, M.; YAZBEK; DI GIOVANNI, 2004). Ainda no começo dessa década, são criados o Programa de Auxílio à Família (1990), em Honduras; o Programa de Erradicação do Trabalho Infantil (PETI) (1996), também no Brasil; o Programa de Educação, Saúde e Alimentação (PROGRESA) (1997), no México; o Programa Nacional de Becas Estudiantiles (1997), na Argentina e o Bono Solidario (1998), no Equador (FONSECA, 2006; STEIN, 2008; COBO, 2012; SILVA, M., 2014).

Segundo Stein (2008), a experiência do México foi alvo de muitos elogios pelos organismos multilaterais, como o Banco Mundial e o Banco Internacional para a Reconstrução e Desenvolvimento (BIRD), e exerceu forte influência sobre os demais países da região, principalmente a partir dos anos 2000, quando se multiplicam as diversas experiências: em Nicarágua, com o Mi Familia (2000); na Costa Rica, com o Superémonos (2000); no Brasil, com a ampliação dos programas nacionais - Bolsa Escola (2001), Bolsa Alimentação (2001), Auxilio Gás (2002), Cartão Alimentação (2003), o Bolsa Família (implementado desde 2003 a partir da unificação dos programas anteriores) -, e a promulgação da Lei n ${ }^{\circ} 10.835$, de 8 de janeiro de 2004, que institui a renda básica de cidadania; na Colômbia, com o Famílias en Acción (2001); no Equador, com o Bono SolidaridadBono de Desarrollo Solidario (2001); na Argentina, com o Jefes y Jefas de Familia (2002); no Chile, com o Chile Solidario (2002); na Jamaica, com o Programa para el Progreso por médio de Salud y Educación (2002); em El Salvador, com o Programa Oportunidades (Red de Protección Social) (2005); no Uruguai, com o Ingreso Ciudadano (2005); no Paraguai, com o Tekoporã (piloto), Nopytyvo (na região do Chaco) (2005); na República Dominicana, com o Solidaridad (2005); no Peru, com Juntos (2005); no Panamá, com o Red de Oportunidades (2006); na Bolívia, com o Bono Escolar (2006); e na Guatemala, com o Mi Bono Seguro (2012) (FONSECA, 2006; STEIN, 2008; COBO, 2012; SILVA, M., 2014).

A ampliação dessa diversidade de programas de renda mínima condicionada na América Latina vem demonstrando que muitos deles se diferenciam entre si pelas condições de acesso; pelo valor, fórmula do cálculo e entrega do benefício; pelo tempo previsto para a permanência dos beneficiários; pelos seus sistemas de seleção, acompanhamento e avaliação; pelos mecanismos de controle social democrático; pelas relações entre os distintos níveis de governos e suas modalidades de financiamento (FONSECA, 2006; STEIN, 2008; SILVA, M., 2014). Entretanto, todos eles possuem características semelhantes, dentre as quais se destacam: a focalização em famílias pobres e extremamente pobres, sobretudo com crianças e adolescentes; a exigência de condicionalidades, principalmente ligadas à saúde e à educação e; o não pertencimento aos direitos sociais, pois são programas de enfrentamento à pobreza, que não se integram aos sistemas de proteção social, como aponta Lavinas (2014, p. 
20), "[...] tais programas de combate à pobreza são ad hoc e não integram efetivamente a institucionalidade dos sistemas de proteção existentes, quaisquer que sejam seus desenhos e escopos".

Além disso, esses programas não asseguram a cobertura de todo o público-alvo, pois o princípio da focalização restringe o acesso. Apesar de enfrentar a extrema pobreza, apenas o aumento do salário e as prestações sociais monetárias vinculadas aos direitos do trabalho têm sido atrelados à redução da pobreza na América Latina em determinadas conjunturas. Logo, os programas de renda mínima condicionada não combatem à pobreza, mas atenuam as falhas de mercado com sua capacidade de promover o consumo de bens e serviços de beneficiários (antes impedidos de realizá-lo), principalmente com a inserção bancária desses segmentos pauperizados, que - com o acesso a serviços e a empréstimos, e experimentando as consequências que, muitas das vezes, tudo isso acarreta, como o pagamento de juros e o endividamento - contribuem assim com a reprodução do capital de dominação financeira (LAVINAS, 2014; SILVA, G., 2009).

Não por acaso, como demonstra Lavinas (2014), que o sistema financeiro na América Latina vem expandindo e facilitando o acesso ao crédito de consumo e ao microcrédito, como também ampliando os seguros privados (na área da saúde, da previdência, do ensino médio, técnico e superior e áreas mais específicas, como cobertura de funeral etc.), que se colocam como uma alternativa à desertificação deixada pelas contrarreformas do Estado neoliberal, cujas políticas sociais universais, mesmo no Brasil, com a introdução da seguridade social na Constituição Federal de 1988, jamais se efetivaram como mecanismo de redistribuição e de promoção da equidade. Assim, parece ser possível afirmar que as configurações atuais dos sistemas de proteção social inconclusos da região tende a privilegiar os interesses do capital de dominação financeira, haja vista que a expansão e monetarização da assistência social pela via dos programas de renda mínima condicionada vêm acompanhada da privatização e da mercantilização das políticas sociais.

\section{Considerações}

Nos países centrais, notou-se que essa também é uma tendência dos sistemas de proteção social, mas ainda hoje os programas de renda mínima buscam complementar as provisões de serviços e outras prestações sociais monetárias. No caso da América Latina, os sistemas de proteção social inconclusos vêm cedendo lugar para os programas de renda mínima condicionada, cuja articulação com as provisões de serviços e prestações sociais monetárias tem sido desafiada pelo déficit de serviços de educação e de saúde em quantidade e em qualidade, pelo processo de privatização e mercantilização das políticas sociais, pelas distintas formas de violência etc.

Assim, a dimensão compensatória da proteção social, desarticulada do conjunto das provisões e prestações sociais, vem ganhando centralidade na América Latina com o investimento concentrado em programas de renda mínima condicionada, que nascem no pós-1980 configurando-se, para muitos trabalhadores e famílias, como a primeira e única forma de recurso. Nos países centrais, identificou-se que os programas de renda mínima surgem articulados às estruturas dos Welfare States e que têm sido a última prestação social monetária a ser demandada, mesmo em um contexto neoliberal marcado por contrarreformas do Estado.

Pôde-se também perceber que desde Thomas More a defesa pela instituição de uma renda mínima tem sido feita por humanistas cristãos, teóricos do socialismo utópico, do liberalismo ortodoxo e heterodoxo, do neoliberalismo e críticos do capitalismo, como André Gorz. Na contemporaneidade, constatou-se que nos países centrais tais propostas e programas, apesar de estarem vinculadas principalmente a determinadas correntes teóricas denominadas de inspiração liberal, distributivista ou progressista e de inserção, assumem um formato híbrido. Na América Latina, estudos têm apontado que nem mesmo os ideólogos do neoliberalismo são contrários a implementar os programas de renda mínima condicionados aos mais pobres, posto que a lógica residual que eles assumem na região não afeta o mercado; pelo contrário, corrige suas falhas, na medida que transforma os pauperizados em consumidores. Entretanto, ao menos no Brasil, as forças progressistas (partidos políticos de esquerda, movimentos, organizações e redes sociais, e entidades profissionais, como a do Serviço Social) vêm defendendo a construção de um Programa de Renda Universal de Cidadania, sem condicionalidades e complementar a um sistema de seguridade social público e universal ${ }^{5}$.

\section{Referências}

BEHRING, E. R.; BOSCHETTI, I. Politica social: fundamentos e história. São Paulo: Cortez, 2006.

BOSCHETTI, I. A política de seguridade social no Brasil. In: ASSOCIAÇÃO BRASILEIRA DE ENSINO E PESQUISA EM SERVIÇO

SOCIAL. Serviço social: direitos sociais e competências profissionais. Brasília. DF: ABEPSS, 2009. p. 323-338.

BOSCHETTI, I. Assistência social e trabalho no capitalismo. São Paulo: Cortez, 2016. 
BRASIL. Lei ${ }^{\circ} 10.835$, de 8 de janeiro de 2004. Institui a renda básica de cidadania e dá outras providências. Diário Oficial da União, Brasília, DF, 9 jan. 2004. Seção 1, p. 1.

COBO, B. Politicas focalizadas de transferência de renda: contextos e desafios. São Paulo: Cortez, 2012.

COMISSÃO ECONÔMICA PARA A AMÉRICA LATINA E O CARIBE. Panorama social de América Latina 2006. Santiago de Chile: Naciones Unidas/CEPAL, 2007. Disponível em: https://www.cepal.org/pt-br/node/25977. Acesso em: 30 jul. 2018.

CONSELHO FEDERAL DE SERVIÇO SOCIAL. $2^{\circ}$ seminário nacional sobre o trabalho do/a assistente social na política de assistência social: em defesa da política de assistência social e do trabalho de assistentes sociais. CFESS Manifesta, Fortaleza, ago. 2018. Disponível em: http://www.cfess.org.br/arquivos/2018-CfessManifesta-2SeminarioAssistencia-Site.pdf. Acesso em: 10 ago. 2018.

COUTINHO, C. N. Contra a corrente: ensaios sobre democracia e socialismo. 2. ed. São Paulo: Cortez, 2008.

FLEURY, S. Estado sem cidadãos: seguridade social na América Latina. Rio de Janeiro: Fiocruz, 1994.

FONSECA, A. M. M. da. Família e política de renda mínima. São Paulo: Cortez, 2001.

FONSECA, A. M. M. da. Los sistemas de protección social en América Latina: un análisis de las transferencias monetarias condicionadas. [S. l.: s. n.], 2 sept. 2006.

HARVEY, D. Condição pós-moderna: uma pesquisa sobre as origens da mudança cultural. 21. ed. São Paulo: Loyola, 2011.

HARVEY, D. O neoliberalismo: história e implicações. São Paulo: Loyola, 2008.

HAYEK, F. A. O caminho da servidão. Rio de Janeiro: Instituto Liberal, 1990.

KEYNES, J. M. How to pay for the war: a radical plan for the Chancellor of the Exchequer. London: Macmillan and Co., 1940.

LAVINAS, L. América Latina: mínimos monetários em lugar de proteção social. Revista Política Social e Desenvolvimento, [s. l.], ano 2, n. 8, p. 18-27, nov. 2014.

LAVINAS, L. Programas de garantia de renda mínima: perspectivas brasileiras. Rio de Janeiro: Instituto de Pesquisa Econômica Aplicada, out. 1998. (Texto para discussão, n. 596).

LENIN, V. I. Imperialismo, estágio superior do capitalismo: ensaio popular. São Paulo: Expressão Popular, 2012.

MARX, K.; ENGELS, F. O manifesto comunista. Rio de Janeiro: Paz e Terra, 1998.

MORE, T. Utopia. Brasília: Editora Universidade de Brasília: Instituto de Pesquisa de Relações Internacionais, 2004.

PAINE, T. La justice agraire opposée à la loi et aux privilèges agraires. Revue du MAUSS, Paris, n. 7, p. 23-36, 1. sem. 1996.

PAINE, T. The Rights of Man. London: J. M. Dent \& Sons; New York: E. P. Dutton \& Co., 1935.

PARTIDO SOCIALISMO E LIBERDADE; PARTIDO COMUNISTA BRASILEIRO. Programa da coligação Vamos Sem Medo de Mudar o Brasil. [S. l.]: PSOL: PCB, [2018]. Disponível em: http://divulgacandcontas.tse.jus.br/candidaturas/oficial/2018/BR/BR/ 2022802018/280000601016/proposta_1533565462424.pdf. Acesso em: 19 dez. 2018.

PASTORINI, A. Elementos orientadores das reformas da proteção social na América Latina. Argumentum, Vitória, v. 2, n. 1, p. 133-149, jan./jun. 2010.

PAULO NETTO, J. Crise do capital e consequências societárias. Serviço Social \& Sociedade, São Paulo, n. 111, p. 413-429, jul./set. 2012. PAULO NETTO, J.; BRAZ, M. Economia política: uma introdução crítica. São Paulo: Cortez, 2006.

PEREIRA, P. A. P. Necessidades humanas: subsídios à crítica dos mínimos sociais. 3. ed. São Paulo: Cortez, 2006.

POLANYI, K. A grande transformação: as origens de nossa época. Rio de Janeiro: Campus, 1980.

SILVA, G. S. da. Capital portador de juros e programas de transferência de renda: monetarização das políticas sociais e contra reforma. Revista de Politicas Públicas, São Luis, v. 13, n. 2, p. 173-181, jul./dez. 2009.

SILVA, M. O. da S. e. (coord.). Programas de transferência de renda na América Latina e Caribe. São Paulo: Cortez, 2014.

SILVA, M. O. da S. e. Renda mínima e reestruturação produtiva. São Paulo: Cortez, 1997.

SILVA, M. O. da S. e; YAZBEK, M. C.; DI GIOVANNI, G. A politica social brasileira no século XXI: a prevalência dos programas de transferência de renda. São Paulo: Cortez, 2004.

SMITH, A. A riqueza das nações: investigação sobre sua natureza e suas causas. São Paulo: Abril Cultural, 1983.

STEIN, R. H. Configuração recente dos programas de transferência de renda na América Latina: focalização e condicionalidade. In: BOSCHETTI, I.; BEHRING, E. R.; SANTOS, S. M. de M. dos.; MIOTO, R. C. T. (org.). Política social no capitalismo: tendências contemporâneas. São Paulo: Cortez, 2008. p. 196-219.

SUPLICY, E. M. Renda básica de cidadania: a resposta dada pelo vento. Porto Alegre: L\&PM, 2006.

SUPLICY, E. M. Renda de cidadania: a saída é pela porta. 3. ed. São Paulo: Cortez, 2004.

VANDERBORGHT, Y, VAN PARIJS, P. Renda básica de cidadania: fundamentos éticos e econômicos. Rio de Janeiro: Civilização Brasileira, 2006.

VIANA, A. L. d'Á.; LEVCOVITZ, E. Proteção social: introduzindo o debate. In: VIANA, A. L. d’Á.; ELIAS, P. E. M.; IBAÑEZ, N. (org.). Proteção social: dilemas e desafios. São Paulo: Hucitec, 2005. p. 15-55.

VIANNA, M. L. T. W. A americanização (perversa) da seguridade social no Brasil: estratégias de bem-estar e políticas públicas. 2. ed. Rio de Janeiro: Revan: IUPERJ/UCAM, 2000.

VIANNA, M. L. T. W. Em torno do conceito de política social: notas introdutórias. Rio de Janeiro: [s. n.], dez. 2002. Disponível em: http://antigo.enap.gov.br/downloads/ec43ea4fMariaLucia1.pdf. Acesso em: 30 jul. 2018.

VIVES, J. L. Tratado del socorro de los pobres. [S. l.]: Clásicos de Historia, [2017]. (Clásicos de Historia, 239). Disponível em: http:/ /clasicoshistoria.blogspot.com/2017/09/juan-luis-vives-tratado-del-socorro-de.html. Acesso em: 30 jul. 2018. 


\section{Notas}

1 Marx e Engels (1998) criticaram as fragilidades das análises dos socialistas utópicos sobre a sociedade burguesa e os meios para transformá-la, pois negligenciavam o materialismo dialético e o proletariado enquanto uma classe revolucionária.

2 "A crise sistêmica se manifesta envolvendo toda a estrutura da ordem do capital. A primeira destas crises emergiu em 1873 [...]. A segunda crise sistêmica que o capitalismo experimentou explodiu em 1929 [...]. Todas as indicações mais sólidas apontam que estamos experimentando, neste momento uma crise que é de natureza sistêmica." (PAULO NETTO, 2012, p. 415-416).

3 De acordo com Coutinho (2008, p. 99-100), “A palavra 'reforma' foi sempre organicamente ligada às lutas dos subalternos para transformar a sociedade e, por conseguinte, assumiu na linguagem política uma conotação claramente progressista e até mesmo de esquerda. O neoliberalismo busca assim utilizar a seu favor a aura de simpatia que envolve a ideia de 'reforma'. É por isso que as medidas por ele propostas e implementadas são mistificatoriamente apresentadas como 'reformas', isto é, como algo progressista em face do 'estatismo' [...]. Estamos assim diante da tentativa de modificar o significado da palavra 'reforma: o que antes da onda neoliberal queria dizer ampliação dos direitos, proteção social, controle e limitação do mercado etc. significa agora cortes, restrições, supressão destes direitos e deste controle”. É por isso que para esse autor "[...] parece mais adequado, para uma descrição dos traços essenciais da época contemporânea, utilizar não o conceito de revolução passiva, mas sim o de contrarreforma". (COUTINHO, 2008, p. 103).

4 De acordo com Boschetti (2016, p. 156), nota-se uma tendência de "[...] mutação no Estado social dos países do capitalismo central, que vem sorrateiramente minando a proteção social vinculada aos direitos do trabalho e avançando na instauração de prestações sociais assistenciais condicionadas a critérios de renda [...]".

5 OConselho Federal de Serviço Social (2018, p. 4) defende a "Seguridade social pública e universal [...]; A Transformação do Bolsa Família em um Programa de Renda Universal de Cidadania sem condicionalidades, com renda per capita para acesso de 1 salário mínimo [...]”. O Programa da Coligação Vamos Sem Medo de Mudar o Brasil: Guilherme Boulos e Sonia Guajajara, da aliança que envolve Partido Socialismo e Liberdade (PSOL), Partido Comunista Brasileiro (PCB), Movimento dos Trabalhadores Sem Teto (MTST), Articulação dos Povos Indígenas do Brasil (APIB), Mídia Ninja e vários outros movimentos sociais, propõe "garantir a todas as pessoas, junto com a redução substantiva da jornada, uma renda básica universal” (PARTIDO SOCIALISMO E LIBERDADE; PARTIDO COMUNISTA BRASILEIRO, [2018], p. 147), como também "[...] reverter toda a privatização da gestão na seguridade social e nas demais políticas sociais [...]" (PARTIDO SOCIALISMO E LIBERDADE; PARTIDO COMUNISTA BRASILEIRO, [2018], p. 154).

\section{Robson Roberto da Silva}

robson.essuff@gmail.com

Doutorado em Serviço Social pela Universidade Federal do Rio de Janeiro (UFRJ)

Professor Adjunto da Escola de Serviço Social da Universidade Federal Fluminense (UFF)

\section{UFF}

Campus do Gragoatá

Rua Prof. Marcos Waldemar de Freitas Reis, s/n, Bloco E - São Domingos

Niterói - Rio de Janeiro - Brasil

CEP: 24.210-201

\section{Agência financiadora \\ Não se aplica.}

\section{Contribuições dos autores}

Não se aplica.

\author{
Consentimento para publicação \\ Não se aplica.
}

\section{Conflito de interesses}

Não há conflito de interesses.

Aprovação por Comitê de Ética e consentimento para parti-

cipação

Não se aplica. 